\title{
Evolved human male preferences for female body shape
}

\author{
Rebecca T Chastain ${ }^{1}$, Daniel Taub²
}

\begin{abstract}
Female body shape has an apparent influence on mate value as perceived by males. Some researchers have suggested that human male mate preference has evolved to universally favor a specific body shape which can be quantified with a particular value for Waist-Hip Ratio and/or Body Mass Index. Other research has presented evidence that populations of males exhibit differentiated preferences for female body shape. The research literature largely supports the hypothesis that male mate preference for female body shape is variable and dependent upon local resource availability. These conclusions provide insight into the evolutionary processes that have acted to produce adaptive flexibility in human male mate preferences in accordance with the environment.
\end{abstract}

While social learning can be expected to play an important

\section{Introduction}

An individual animal's reproductive success depends, in part, on the selection of a high-quality mate; this can be achieved by selecting mates that exhibit characteristics such as good nutrition, high genetic quality, status, youth, and health. ${ }^{[1]}$ As many such characters are not directly observable (such as a potential mate's genome or vitamin deficiencies), individuals usually choose mates based on a set of cues that they have evolved to use. ${ }^{[2]}$. For example, a female peafowl can use the size, maintenance, and overall quality of a male's plumage to infer things about his status, resource availability, health, and so on. ${ }^{[3]}$ However, in order for a population to evolve to use them, these cues must be honest indicators, meaning they cannot be reliably imitated by inferior individuals; if plumage was not an honest indicator of health, status, etc. in peafowl, there would be no evolutionary advantage conferred to the female that chose it, and therefore no selective force to drive evolution. ${ }^{[2]}$

For human males, female body shape may be an important metric by which mate value is evaluated.
${ }^{1}$ Southwestern University, 1001 East University Ave., Georgetown, Texas 78626, United States

*Author correspondence: taubd@southwestern.edu

Licensed under: CC-BY 4.0

Received 02-06-2020; accepted 12-01-2021

role in the development of individual human mate preferences (e.g. ${ }^{[4]}$ ), questions concerning a possible role of evolution in the development of male mate preferences for female body shape have stimulated an active field of research. ${ }^{[5]}$ It is this literature that we review here. We discuss all research papers that we aware of that both 1) present data on human male preferences or judgements comparing real or simulated female torso shape or proportions or Body Mass Index (BMI), and 2) interpret this data in an evolutionary context. Some research on evolved male human mate preferences has focused on breast size or shape. ${ }^{[6][7][8]}$ This includes the suggestion in the earlier literature that human breasts evolved as sexual signals that mimicked buttocks during a transition to face to face copulation as a common human behavior. ${ }^{[9][10]}$ However, a number of

\footnotetext{
1 of 6 | WikiJournal of Science
} 
studies have found that the influence of breast size on male mate preferences is dependent on measures of overall body dimensions. ${ }^{[11][12][13]}$ These measures include the waist to hip ratio ratio (WHR: the ratio of the circumference of the waist to the circumference of the hips), and body mass index (BMI: an individual's weight in kilograms divided by the square of their height in meters). Of these measures, BMI is often a much stronger

predictor of attractiveness.[14][155][16][17][18][19]) WHR does not always reach statistical significance with respect to its influence on attractiveness rating. ${ }^{[13][20][21][22]}$

At present, hypotheses about these measures can be loosely divided into variations on the idea that male mate preferences for female body shape have evolved to use specific, universal cues (e.g. ${ }^{[23]}$ ) or that male mate preferences for female body shape have evolved to respond differently to cues depending on resource availability (e.g. ${ }^{[18]}$ ).

\section{There is an evolved universal preference for a specific female body shape}

Some research on the impact of female body shape on male mate preference hypothesizes that there exists a universal evolved ideal (e.g. [24][25][26][23][27][28]). Singh (1993a, 1993b) found that the optimal waist-to-hip ratio (the ratio of the circumference of the waist to the circumference of the hips; also called WHR) for attracting males is 0.7 , and concluded that this value is an honest cue which represents a universal, evolved body measurement preference. ${ }^{[24][25]}$ However, the subjects of the relevant portion of this study were limited to include only American college students, ${ }^{[24][25]}$ casting some doubt on the study's applicability to other types of populations. Other studies conducted on homogenous (most frequently college-educated western) populations have found similar results. For example, one centering on British university students also concluded that a WHR of 0.7 was an evolved universal preference (see ${ }^{[23]}$; for a more recent example, see ${ }^{[29]}$ ). Universal preferences for other body measurements have been proposed as well. For example, universal preferences for body mass index (an individual's weight in kilograms divided by the square of their height in meters; also called BMI) have been posited, usually in the range of 17-19. However, these studies have also focused on a limited range of mostly fairly affluent and educated populations, for example, Malaysian college students; ${ }^{\left[{ }^{[28]}\right.}$ Americans; ${ }^{[13]}$ or British undergraduates, ${ }^{[14]}$ potentially precluding an inference that these preferences are truly universal. ${ }^{[30]}$

The hypothesis that an evolved, universal preference for female body shape exists is sometimes extended to claim that males have evolved to hold an ideal for curvaceousness in females that exists in few, if any, real women. ${ }^{[13]\left[3^{1}\right]}$ This phenomenon of a preference for mates with traits outside those of the normal range within a species (also known as supernormal stimuli) has been documented in many species, such as the Pied Flycatcher, which shows a preference for investing in clutches in which a deeply colored fake egg has been placed among the somewhat paler real eggs. ${ }^{[32]}$

2

When applied to human mate selection, these claims often center on comparing real and fictional women. For example, Lassek and Gaulin (2016) compared attractiveness ratings within and between three groups consisting respectively of fictional women, Playboy Bunnies, and average women, finding that imaginary women were chosen as the most attractive by college students. ${ }^{[13]}$ Additionally, the most attractive figures, such as the fictional characters Jessica Rabbit and Lara Croft, universally exhibited a lower WHR and a smaller waist than the highly attractive real women represented by the Playboy Bunnies. Lassek and Gaulin (2016) posited that for real women, the perceived attractiveness of extremely thin individuals is low, due to associated cues of malnutrition, such as jutting bones. ${ }^{[13]}$ Fictional women are seen as more attractive because they can be depicted as unnaturally smallwaisted without cues of poor health. Fictional women that are drawn or animated to appeal sexually to male audiences tend to share this trend of unnaturally feminine body shapes. For example, comic books are frequently criticized for depicting unattainably small waists for the benefit of the male gaze. ${ }^{[33][34]}$ Evidence of the appeal of supernormal stimuli can be extended to real women as well. One example is that of surgically augmented breasts, which have been found to elicit a stronger response from male viewers than natural breasts ( ${ }^{[35]}$; see also ${ }^{[31]}$ ). 
There is no universal evolved preference for a specific female body shape

\section{Evidence for lack of universality in preferences for female body shape}

The hypothesis that males have evolved a cross-cultural universal preference for certain female body shape cues has been challenged by a large body of evidence demonstrating differences in female body shape pref-

erence between populations.([20][21][22][15][16][12][5][36][19]) For example, a study conducted in 1999 on the Hadza people of Tanzania found they preferred higher WHRs than those posited to be universally preferable. ${ }^{[37]}$ Another found that South African Zulu men's preferences varied significantly from both Black and Caucasian British men. ${ }^{[22]}$ Sugiyama (2004) concluded that men of the Shiwiar indigenous group of Ecuador preferred women that were heavier than average within their own population, directly challenging assertions that thin, smallwaisted women are a universal ideal. ${ }^{[38]}$

It has often been suggested that the same body types do not hold equal evolutionary advantage in all contexts. Females with larger fat stores, and therefore higher BMI, higher WHR, larger waist, etc., may have an advantage over thinner females during periods of resource insecurity, which were common to the huntergatherer system humans operated within for nearly their entire evolutionary history. ${ }^{[39]}$ This casts doubt over the idea that male preference for a smallwaisted, low BMI female body shape could have evolved towards universality. Additionally, because most of human evolution took place in contexts with high levels of resource insecurity, is unlikely that a universal, static evolved preference, if such a thing were to exist, would reflect a preference for the cues indicating success in modern, resource-abundant environments. ${ }^{[30]}$

\section{Evidence that male mate preference for female body shape has evolved to vary predictably by population with resource availability}

Variation in female body shape preferences could be indicative of the body type representative of success in

of 6 | WikiJournal of Science the local environment, such that males in rural or lowsocioeconomic environments (SES) will favor heavier females because being heavy is indicative of higher resource acquisition relative to the population when resources are scarce and hunger is common.[39] Conversely, males in urban or high-SES environments will favor thinner females because being thin in highSES environments indicates access to healthy, expensive food and leisure time for exercise.[30][36][39] A male who always preferred a specific body shape would be at a disadvantage in any context in which that shape does not indicate success and health.[30] Plasticity in the use of body shape cues to determine preference would confer an evolutionary advantage to the male, allowing him to choose a body type that reflects higher mate value regardless of environmental circumstance.

As an example of this phenomenon, Swami and Tovée (2005) compared the attractiveness ratings given to photographs of real women by Caucasian British students and Malaysian immigrants to Britain who had lived in Britain for at least two years, as well as three groups of Malayasian individuals living in Kuala Lumpur (a large, wealthy city), Kota Kinabalu (a small, poor city), and various rural villages.[18] They found that the preferred values for BMI and WHR increased as socioeconomic status decreased for each population, and that rural populations preferred

\section{3}

heavier females than did the urban populations. This finding has been replicated across other populations. For example, high-SES Thai residents of Bangkok and Thai immigrants to Britain identified a nearly identical ideal BMI of about 20.5 while low-SES Thai individuals living in the rural Chiang Rai region preferred a BMI of 23.77.[20] Additionally, the rural Sámi, an indigenous people of Finland, preferred women with a BMI of around 25 as opposed to non-Sámi individuals living in Helsinki or urban areas of Britain, who indicated a peak BMI value of around 20-21.[21]

Another study found that even among the Samoan people, who traditionally celebrate larger female forms, there are significant differences in how people from high- and low-SES areas perceive the attractiveness of women with high BMI and WHR values. Swami et al. (2007) surveyed a low-SES status Samoan population, a high-SES Samoan population, 
and a British population and found that they all indicated the same ideal BMI (approximately 21).[17] However, the British and high-SES Samoan populations both found larger women to be dramatically less attractive than the ideal, while the low-SES population did not.

These studies, taken together, provide notable evidence for socioeconomic/resource-availability dependent plasticity in male mate preferences for female body shape. However, this resource availability pattern may not be universal. While Swami et al. (2010) found the predicted differences in the ideal BMI preferred by urban and rural populations in both Malaysia and South Africa, they also found that the differences between rural and urban Austrians were not significant.[5] They suggested a few possible explanations for this, including that this result could be due to the fact that they compared a community sample (Drösing) to a college sample (Vienna) or that differences in SES must reach a certain threshold in order to significantly impact male use of female body shape cues. In support of the second explanation, it should be noted that in addition to being a wealthier country than Malaysia and South Africa,[40] Austria also has less income inequality.[41]

The impact of resource availability on male mate preferences may be measurable on an individual basis as well as across populations, indicating that plasticity between populations is explicable as the resultant average of each individual male's evolved plasticity in mate preference reacting with their personal perception of resource availability (e.g. [42]). Nelson and Morrison (2005), for example, found that men who were primed to feel poor, either because they have been made to feel that they are not carrying much money on their person or have been told they have below-average savings, prefer heavier women than men who are made to feel that they are more financially secure than others.[43] They also found that hungry men prefer heavier women than do satiated men and suggested that these preferences are due to an adaptive response to physiological cues of resource scarcity. Other studies have noted a similar impact of hunger on male mate preference, $[44][45][46][47][48]$ suggesting that hunger is likely one of the evolved cues used by males to adjust mate preference.

of 6 | WikiJournal of Science

\section{Relationships between different female body measurements and attractiveness}

Exactly how different female body shape measures (including BMI, WHR, weight, waist size, hip size, bust size, waist size to height ratio, curvaceousness, hip to height ratio, thigh to height ratio, bust to height ratio, etc.) correlate to attractiveness ratings is debated. Although some researchers do suggest that waist size, ${ }^{[49][50]}$ waist to height ratio, ${ }^{[13]}$ curvaceousness, ${ }^{[51][52]}$ or other less common measures are better predictors of attractiveness rating than $\mathrm{BMI}$ and $\mathrm{WHR}$, their infrequent usage by researchers complicates evaluation of their ecological validity.

Between BMI and WHR, the two most popularly used metrics in female body shape and attractiveness studies, the literature favors BMI as a cue, as it appears to have a stronger correlation with attractiveness than WHR.([53][54][18][22]][44][15][177][55][56][22]) However, BMI and WHR are often correlated (e.g. ${ }^{[57][58]}$ ), as are BMI and many of body shape measurements that have been proposed as possible attractiveness cues. ${ }^{[13]}$ One notable exception is Singh et al. (2010), which found that when BMI is held constant while WHR is altered, WHR has a stronger predictive power for attractiveness ratings. ${ }^{[26]}$

Additionally, which of these measurements are actually used as cues is questionable. For example, BMI is not a

directly observable trait, ${ }^{[13]}$ it is an abstraction of the relationship between an individual's height and weight, and it is therefore unlikely to be used as a direct criterion for evaluating a female's mate value. Furthermore, WHR and BMI may not be viable as evolved cues simply

\section{4}

because they are not necessarily honest indicators of health and fertility. For example, evidence has been gathered indicating that females exhibiting the proposed universally ideal characteristics (very low WHR and BMI) have lower reproductive fitness than their

somewhat larger counterparts. ${ }^{[30][59][60]}$

Female body shape is also certainly not the only factor taken into account in determining mate preferences, and may not be the most important cue used in a context-rich environment. Everything from humor and 
intelligence to religion and educational attainment to personal perception of one's own attractiveness and the size of the group of available women all appear to have an impact on mate preference (e.g. ${ }^{[6][6][62][63][64]}$ ). Nonetheless, body shape is likely to play some role in human mate preferences. For example, Lippa (2007) found that $43 \%$ of male respondents indicated that good looks (which must include body shape to some unknown degree), was one of their top three desired traits in a partner (though ranked lower than intelligence). ${ }^{[61]}$

Additionally, there are questions of how closely the body shape preferences tests used in studies correspond to real-world assessments of body shape. In order to attain attractiveness ratings, participants must be shown representations of female body shapes. The earliest test stimuli used in female body shape research were line drawings (simple, two-dimensional depictions of women), which attempt to depict variation in the measurement cue of interest. ${ }^{[24]}$ These have been criticized for lack of ecological validity, partly because drawings can depict supernormal proportions without concurrent depictions of malnutrition. ${ }^{[13][54]}$ Instead, some have suggested the use of photographs of real women as stimuli, ${ }^{[56][54][7]][65]}$ which has the advantage of including any cue that can be represented in an image of a real woman. Other types of stimuli have been proposed as well, for example, 3D models made from scans of actual women. ${ }^{\left[{ }^{53}\right]\left[5^{\circ}\right]}$ Another set of researchers has opted to use mannequins that could be touched, allowing for the use of tactilely perceived shape cues, though it should be noted that their participants were blind.[66]

Moreover, drawing vs photograph is not the only choice that needs to be made when selecting stimuli. It has been suggested, for example, that a profile view of stimuli has more ecological validity than a frontal view because it accounts for buttocks size as an important aspect of WHR as an evolved cue. ${ }^{[67][54][122]}$ Other suggestions have included that the race of the women depicted in the stimuli might impact their attractiveness ratings; ${ }^{[12]}$ and that stimuli should cover a wider range of possible measurements. ${ }^{[13]}$

\section{Additional information}

\section{Competing interests}

The authors declare that they have no competing interests.

\section{Ethics statement}

No ethics statement necessary.

\section{References}

1. Jaffe, Klaus (2002-03-01). "On Sex, Mate Selection, and Evolution: An Exploration". Comments on Theoretical Biology 7 (2): 91-107. doi:10.1080/08948550214387. ISSN 0894-8550.

2. Miller, G. F. (1997). "Mate choice: from sexual cues to cognitive adaptations". Ciba Foundation Symposium 208: 71-82; discussion 82-87. doi:10.1002/9780470515372.ch6. ISSN 0300-5208. PMID 9386908.

3. Loyau, Adeline; Saint Jalme, Michel; Cagniant, Cécile; Sorci, Gabriele (2005-05-03). "Multiple sexual advertisements honestly reflect health status in peacocks (Pavo cristatus)". Behavioral Ecology and Sociobiology 58 (6): 552-557. doi:10.1007/s00265-005-0958-y. ISSN 0340-5443.

4. Little, Anthony C.; Jones, Benedict C.; DeBruine, Lisa M.; Caldwell, Christine A. (2011-02-12). "Social learning and human mate preferences: a potential mechanism for generating and maintaining between-population diversity in attraction". Philosophical Transactions of the Royal Society B: Biological Sciences 366 (1563): 366-375. doi:10.1098/rstb.2010.0192. ISSN og62-8436.

5. Swami, Viren; Frederick, David A.; Aavik, Toivo; Alcalay, Lidia; Allik, Jüri; Anderson, Donna; Andrianto, Sonny; Arora, Arvind et al. (2010-03). "The Attractive Female Body Weight and Female Body Dissatisfaction in 26 Countries Across 10 World Regions: Results of the International Body Project I". Personality and Social Psychology Bulletin 36 (3): 309-325. doi:10.1177/0146167209359702. ISSN 0146-1672.

6. Lynn, Michael (2008-06-10). "Determinants and Consequences of Female Attractiveness and Sexiness: Realistic Tests with Restaurant Waitresses". Archives of Sexual Behavior 38 (5): 737-745. doi:10.1007/s10508-008-9379o. ISSN $0004-0002$.

7. Zelazniewicz, Agnieszka M.; Pawlowski, Boguslaw (2011-10-06). "Female Breast Size Attractiveness for Men as a Function of Sociosexual Orientation (Restricted vs. Unrestricted)". Archives of Sexual Behavior 40 (6): 1129-1135. doi:10.1007/s10508-011-9850-1. ISSN 0004-0002.

8. Kościński, Krzysztof (2019-06-24). "Breast firmness is of greater importance for women's attractiveness than breast size". American Journal of Human Biology 31 (5). doi:10.1002/ajhb.23287. ISSN 1042-0533.

9. Morris, Desmond (1967). The naked ape. A zoologist's study of the human animal. Toronto: Bantam Books. OCLC 1154106000.

10. Cant, J. G. (1981-02). "Hypothesis for the Evolution of Human Breasts and Buttocks". The American Naturalist 117 (2): 199-204. doi:10.1086/283699. ISSN $0003-0147$.

11. Furnham, Adrian; Dias, Melanie; McClelland, Alastair (1998). "The role of body weight, waist-to-hip ratio, and breast size in judgments of female attractiveness". Sex Roles 39 (3/4): 311-326. doi:10.1023/a:1018810723493. ISSN $0360-0025$

12. Swami, Viren; Jones, John; Einon, Dorothy; Furnham, Adrian (2009-05). "Men's preferences for women's profile waist-to-hip ratio, breast size, and ethnic group in Britain and South Africa". British Journal of Psychology 100 (2): 313-325. doi:10.1348/000712608×329525. ISSN 0007-1269.

13. Lassek, William D.; Gaulin, Steven J. C. (2016-04-22). "What Makes Jessica Rabbit Sexy? Contrasting Roles of Waist and Hip Size". Evolutionary Psychology 14 (2): 147470491664345. doi:10.1177/1474704916643459. ISSN 1474-7049.

14. Tovée, M. J.; Maisey, D. S.; Emery, J. L.; Cornelissen, P. L. (1999-01-22). "Visual cues to female physical attractiveness". Proceedings of the Royal Society of London. Series B: Biological Sciences 266 (1415): 211-218. 
doi:10.1098/rspb.1999.0624. ISSN 0962-8452. PMID 10097394. PMC PMC1689653.

15. Swami, Viren; Antonakopoulos, Nicholas; Tovée, Martin J.; Furnham, Adrian (2006-02). "A Critical Test of the Waist-to-Hip Ratio Hypothesis of Women's Physical Attractiveness in Britain and Greece". Sex Roles 54 (34): 201-211. doi:10.1007/s11199-006-9338-3. ISSN 0360-0025

16. Swami, Viren; Caprario, Carolina; Tovée, Martin J.; Furnham, Adrian (200601). "Female physical attractiveness in Britain and Japan: a crosscultural study". European Journal of Personality 20 (1): 69-81. doi:10.1002/per.568. ISSN 0890-2070.

17. Swami, Viren; Knight, Daniel; Tovée, Martin J.; Davies, Patrick; Furnham, Adrian (2007-06). "Preferences for female body size in Britain and the South Pacific". Body Image 4 (2): 219-223. doi:10.1016/j.bodyim.2007.01.002. ISSN 1740-1445.

18. Swami, Viren; Tovée, Martin J. (2005-06). "Female physical attractiveness in Britain and Malaysia: A cross-cultural study". Body Image 2 (2): 115-128. doi:10.1016/j.bodyim.2005.02.002. ISSN 1740-1445

19. Sorokowski, Piotr; Kościński, Krzysztof; Sorokowska, Agnieszka; Huanca, Tomas (2014-08-22). "Preference for Women's Body Mass and Waist-toHip Ratio in Tsimane' Men of the Bolivian Amazon: Biological and Cultural Determinants". PLOS ONE 9 (8): e105468. doi:10.1371/journal.pone.0105468. ISSN 1932-6203.

20. Swami, Viren; Tovée, Martin J. (2007-03). "Differences in attractiveness preferences between observers in low- and high-resource environments in Thailand". Journal of Evolutionary Psychology 5 (1): 149-160. doi:10.1556/jep.2007.1005. ISSN 1789-2082.

21. Swami, Viren; Tovée, Martin J. (2007-02). "Perceptions of female body weight and shape among indigenous and urban Europeans". Scandinavian Journal of Psychology 48 (1): 43-50. doi:10.1111/j.14679450.2006.00526.x. ISSN 0036-5564.

22. Tovee, M; Swami, V; Furnham, A; Mangalparsad, R (2006-11). "Changing perceptions of attractiveness as observers are exposed to a different culture". Evolution and Human Behavior 27 (6): 443-456. doi:10.1016/j.evolhumbehav.2006.05.004. ISSN 1090-5138.

23. Furnham, Adrian; Tan, Tina; McManus, Chris (1997-04). "Waist-to-hip ratio and preferences for body shape: A replication and extension". Personality and Individual Differences 22 (4): 539-549. doi:10.1016/s01918869(96)00241-3. ISSN 0191-8869.

24. Singh, Devendra (1993). "Adaptive significance of female physical attractiveness: Role of waist-to-hip ratio.". Journal of Personality and Social Psychology 65 (2): 293-307. doi:10.1037/0022-3514.65.2.293. ISSN 19391315 .

25. Singh, Devendra (1993-09). "Body shape and women's attractiveness". Human Nature 4 (3): 297-321. doi:10.1007/bfo2692203. ISSN 1045-6767.

26. Singh, Devendra; Dixson, B.J.; Jessop, T.S.; Morgan, B.; Dixson, A.F. (201005). "Cross-cultural consensus for waist-hip ratio and women's attractiveness". Evolution and Human Behavior 31 (3): 176-181. doi:10.1016/j.evolhumbehav.2009.09.001. ISSN 1090-5138.

27. Saad, Gad (2008-07). "Advertised Waist-to-Hip Ratios of Online Female Escorts". International Journal of e-Collaboration 4 (3): 40-50. doi:10.4018/jec.2008070103. ISSN 1548-3673.

28. Stephen, Ian D.; Perera, A. Treshi-Marie (2014-01-20). "Judging the Difference between Attractiveness and Health: Does Exposure to Model Images Influence the Judgments Made by Men and Women?". PLoS ONE 9 (1): e86302. doi:10.1371/journal.pone.0086302. ISSN 1932-6203.

29. Cloud, Jaime M.; Perilloux, Carin (2015-05-07). "'Drawing" Conclusions About Perceptions of Ideal Male and Female Body Shapes". Evolutionary Psychological Science 1 (3): 163-171. doi:10.1007/\$40806-015-0020-x. ISSN 2198-9885.

30. Bovet, Jeanne (2019-06-04). "Evolutionary Theories and Men's Preferences for Women's Waist-to-Hip Ratio: Which Hypotheses Remain? A Systematic Review". Frontiers in Psychology 10 doi:10.3389/fpsyg.2019.01221. ISSN 1664-1078.

31. Markovic, Slobodan; Bulut, Tara (2017). "Attractiveness of the female body: Preference for the average or the supernormal?". Psihologija 50 (3): 403-426. doi:10.2298/psi1703403m. ISSN 0048-5705.

32. Moreno, Juan; Lobato, Elisa; Merino, Santiago; Martínez-de la Puente, Josué (2008-11). "Blue-Green Eggs in Pied Flycatchers: An Experimental Demonstration that a Supernormal Stimulus Elicits Improved Nestling
Condition". Ethology $\quad 114 \quad$ (11): $1078-1083$. doi:10.1111/j.14390310.2008.01551.x. ISSN 0179-1613.

33. Burch, Rebecca L.; Johnsen, Laura (2020-04). "Captain Dorito and the bombshell: Supernormal stimuli in comics and film.". Evolutionary Behavioral Sciences 14 (2): 115-131. doi:10.1037/ebsoooo164. ISSN 23302933.

34. Cocca, Carolyn (2014-05-16). "The 'Broke Back Test': a quantitative and qualitative analysis of portrayals of women in mainstream superhero comics, 1993-2013". Journal of Graphic Novels and Comics 5 (4): 411-428. doi:10.1080/21504857.2014.916327. ISSN 2150-4857.

35. Doyle, James; Pazhoohi, Farid (2012). "Natural and Augmented Breasts: Is what is not natural most attractive?". Human Ethology Bulletin 27 (4): 4-14. ISSN 2224-4476.

36. Anderson, Judith L.; Crawford, Charles B.; Nadeau, Joanne; Lindberg, Tracy (1992-05). "Was the Duchess of windsor right? A cross-cultural review of the socioecology of ideals of female body shape". Ethology and Sociobiology 13 (3): 197-227. doi:10.1016/0162-3095(92)90033-z. ISSN 0162-3095.

37. Wetsman, Adam; Marlowe, Frank (1999-07). "How Universal Are Preferences for Female Waist-to-Hip Ratios? Evidence from the Hadza of Tanzania". Evolution and Human Behavior 20 (4): 219-228. doi:10.1016/s1090-5138(99)00007-0. ISSN 1090-5138.

38. Sugiyama, Lawrence S. (2004-01). "Is beauty in the context-sensitive adaptations of the beholder?". Evolution and Human Behavior 25 (1): 5162. doi:10.1016/s1090-5138(03)00083-7. ISSN 1090-5138.

39. Brown, Peter; Konner, Melvin (2006-12-17). "An Anthropological Perspective on Obesity". Annals of the New York Academy of Sciences 499 (1): 29-46. doi:10.1111/j.1749-6632.1987.tb36195.x. ISSN 0077-8923.

40. "Global wealth databook 2019" (PDF). Credit Suisse. 2019-10-01. Archived from the original (PDF) on 2019-10-23.

41. "Human Development Report 2009: Overcoming barriers: Human mobility and development". hdr.undp.org. United Nations. 2009. Retrieved 2021-0111.

42. Brase, Gary L.; Walker, Gary (2004-06). "Male sexual strategies modify ratings of female models with specific waist-to-hip ratios". Human Nature 15 (2): 209-224. doi:10.1007/s12110-004-1020-x. ISSN 1045-6767.

43. Nelson, Leif D.; Morrison, Evan L. (2005-02). "The Symptoms of Resource Scarcity". Psychological Science $16 \quad$ (2): 167-173. doi:10.1111/j.09567976.2005.00798.x. ISSN 0956-7976.

44. Swami, Viren; Poulogianni, Katia; Furnham, Adrian (2006). "The Influence of Resource Availability on Preferences for Human Body Weight and NonHuman Objects". Journal of Articles in Support of the Null Hypothesis 4 (1): 17-28. ISSN $1539-8714$.

45. Swami, Viren; Tovée, Martin J. (2006-08). "Does hunger influence judgments of female physical attractiveness?". British Journal of Psychology 97 (3): 353-363. doi:10.1348/000712605×80713. ISSN 00071269.

46. Saxton, Tamsin; McCarty, Kristofor; Caizley, Jasmine; McCarrick, Dane; Pollet, Thomas Victor (2019-08-02). "Hungry People Prefer Larger Bodies and Objects: The Importance of Testing Boundary Effects". British Journal of Psychology 111 (3): 492-507. doi:10.1111/bjop.12417. ISSN 0007-1269.

47. Pettijohn, Terry F.; Jungeberg, Brian J. (2004-09). "Playboy Playmate Curves: Changes in Facial and Body Feature Preferences Across Social and Economic Conditions". Personality and Social Psychology Bulletin 30 (9): 1186-1197. doi:10.1177/0146167204264078. ISSN 0146-1672.

48. Pettijohn, Terry F.; Sacco, Donald F.; Yerkes, Melissa J. (2009-09). "Hungry people prefer more mature mates: A field test of the environmental security hypothesis.". Journal of Social, Evolutionary, and Cultural Psychology 3 (3): 216-232. doi:10.1037/hoog9321. ISSN 1933-5377.

49. Brooks, Robert C.; Shelly, Juliette P.; Jordan, Lyndon A.; J.W. Dixson, Barnaby (2015-09). "The multivariate evolution of female body shape in an artificial digital ecosystem". Evolution and Human Behavior 36 (5): 351-358. doi:10.1016/j.evolhumbehav.2015.02.001. ISSN 1090-5138.

50. Rilling, James K.; Kaufman, Torrey L.; Smith, E.O.; Patel, Rajan; Worthman, Carol M. (2009-01). "Abdominal depth and waist circumference as influential determinants of human female attractiveness". Evolution and Human Behavior 30 (1): 21-31. doi:10.1016/j.evolhumbehav.2008.08.007. ISSN 1090-5138.

51. Voracek, M. (2002-12-21). "Shapely centrefolds? Temporal change in body measures: trend analysis". BMJ 325 (7378): $1447-1448$. doi:10.1136/bmj.325.7378.1447. ISSN 0959-8138. 
52. Fisher, Maryanne $L_{i}$ Voracek, Martin (2006-06). "The shape of beauty: determinants of female physical attractiveness". Journal of Cosmetic Dermatology 5 (2): 190-194. doi:10.1111/j.1473-2165.2006.00249.x. ISSN 1473-2130.

53. Fan, J.; Liu, F.; Wu, J.; Dai, W. (2004-02-22). "Visual perception of female physical attractiveness". Proceedings of the Royal Society of London. Series B: Biological Sciences 271 (1537): 347-352. doi:10.1098/rspb.2003.2613. ISSN $0962-8452$.

54. Tovée, Martin J.; Cornelissen, Piers L. (2001-05). "Female and male perceptions of female physical attractiveness in front-view and profile".

British Journal of Psychology $92 \quad$ (2): $391-402$. doi:10.1348/000712601162257. ISSN 0007-1269.

55. Swami, Viren; Miller, Rebecca; Furnham, Adrian; Penke, Lars; Tovée, Martin J. (2008-01). "The influence of men's sexual strategies on perceptions of women's bodily attractiveness, health and fertility". Personality and Individual Differences 44 (1): 98-107. doi:10.1016/j.paid.2007.07.017. ISSN 0191-8869.

56. Tovée, Martin J.; Hancock, Peter J. B.; Mahmoodi, Sasan; Singleton, Ben R. R.; Cornelissen, Piers L. (2002-11-07). "Human female attractiveness: waveform analysis of body shape". Proceedings of the Royal Society of London. Series B: Biological Sciences 269 (1506): 2205-2213. doi:10.1098/rspb.2002.2133. ISSN 0962-8452.

57. Cornelissen, Piers L.; Toveé, Martin J.; Bateson, Melissa (2009-02). "Patterns of subcutaneous fat deposition and the relationship between body mass index and waist-to-hip ratio: Implications for models of physical attractiveness". Journal of Theoretical Biology 256 (3): 343-350. doi:10.1016/j.jtbi.2008.09.041. ISSN 0022-5193.

58. Doustjalal, Saeid Reza; Gujjar, Kumar Raghav; Sharma, Ratika; Nurfatiha, M.; Firzanah, R. Nur; Syukri, M. K. Muhamad; Napatr, W. A.; Syahirah, T. K. Z. Nurul et al. (2016). "Correlation Between Body Mass Index (BMI) and Waist to Hip Ratio (WHR) among Undergraduate Students". Pakistan Journal of Nutrition 15 (7): 618-624. doi:10.3923/pjn.2016.618.624. ISSN 1680-5194.

59. Lassek, William D.; Gaulin, Steven J. C. (2018-10-01). "Do the Low WHRs and BMls Judged Most Attractive Indicate Better Health?". Evolutionary Psychology 16 (4): 147470491880399. doi:10.1177/1474704918803998. ISSN 1474-7049.

6o. Lassek, William D.; Gaulin, Steven J. C. (2018-10-01). "Do the Low WHRs and BMls Judged Most Attractive Indicate Higher Fertility?". Evolutionary Psychology 16 (4): 147470491880006. doi:10.1177/1474704918800063. ISSN 1474-7049.

61. Lippa, Richard A. (2007-03-23). "The Preferred Traits of Mates in a CrossNational Study of Heterosexual and Homosexual Men and Women: An Examination of Biological and Cultural Influences". Archives of Sexual Behavior 36 (2): 193-208. doi:10.1007/s10508-006-9151-2. ISSN 00040002.

62. Li, Norman P.; Kenrick, Douglas T. (2006). "Sex similarities and differences in preferences for short-term mates: What, whether, and why.". Journal of Personality and Social Psychology 9o (3): 468-489. doi:10.1037/00223514.90.3.468. ISSN 1939-1315.

63. Lenton, Alison P.; Francesconi, Marco (2010-03-09). "How Humans Cognitively Manage an Abundance of Mate Options". Psychological Science 21 (4): 528-533. doi:10.1177/0956797610364958. ISSN 0956-7976.

64. Lenton, Alison P.; Francesconi, Marco (2011-03-02). "Too much of a good thing? Variety is confusing in mate choice". Biology Letters 7 (4): 528-531. doi:10.1098/rsbl.2011.0098. ISSN 1744-9561.

65. Henss, Ronald (2000-03). "Waist-to-hip ratio and female attractiveness. Evidence from photographic stimuli and methodological considerations". Personality and Individual Differences 28 (3): 501-513. doi:10.1016/s01918869(99)00115-4. ISSN 0191-8869.

66. Karremans, Johan C.; Frankenhuis, Willem E.; Arons, Sander (2010-05). "Blind men prefer a low waist-to-hip ratio". Evolution and Human Behavior 31 (3): 182-186. doi:10.1016/j.evolhumbehav.2009.10.001. ISSN 10905138.

67. Marlowe, Frank; Apicella, Coren; Reed, Dorian (2005-11). "Men's preferences for women's profile waist-to-hip ratio in two societies". Evolution and Human Behavior 26 (6): 458-468. doi:10.1016/j.evolhumbehav.2005.07.005. ISSN 1090-5138. 